\title{
Scedosporium apiospermium keratitis: a case report
}

\author{
Umut Karaca ${ }^{*}$ (i)
}

\begin{abstract}
Background: Scedosporium apiospermum, an opportunistic and filamentous fungus, is a rarely seen ocular entity that is difficult to identify and heal. We report a challenging case of S. apiospermium keratitis and discuss the treatment modalities in light of previous studies.

Case presentation: A 30-year-old Turkish farmer with a history of contact lens misuse presented to our clinic with a painful corneal abscess and severe vision loss in his left eye. S. apiospermum was identified by spectrophotometric analysis. The patient was successfully treated with therapeutic penetrating keratoplasty, but was resistant to fluconazole and amphotericin B and susceptible but unresponsive to voriconazole.

Conclusion: S. apiospermum keratitis should be considered in the differential diagnosis of immunocompromised and immunocompetent patients with history of ocular trauma and contact lens use, especially those who do not respond to treatment.
\end{abstract}

Keywords: Scedosporium infection, Mycotic keratitis, Penetrating keratoplasty, Contact lens associated

\section{Introduction}

Fungal keratitis (also known as mycotic keratitis or keratomycosis), which is usually characterized by corneal epitheliopathy and stromal infiltration, especially with Fusarium and Aspergillus species, remains a challenge for ophthalmologists worldwide. It is more common in agricultural and developing countries, with an estimated global prevalence of approximately 1-1.2 million cases annually [1]. Nepal is a worsening example, with an estimated prevalence of $73 / 100,000,27-62 \%$ of which is microbial keratitis, while in Turkey, the estimated incidence of fungal keratitis is $33 / 100,000$ annually [2, 3]. Ocular trauma is the most common predisposing risk factor, particularly during vegetative contamination.

Pathogenic Scedosporium species, including Scedosporium prolificans and Scedosporium apiospermum, cause a wide range of clinical manifestations, from subclinical infection to severe respiratory disease, especially colonization of the respiratory tract [4]. S. apiospermum (also known as the asexual form of the ascomycete Pseudallescheria boydii) is a significant opportunistic pathogen that causes serious infections with very high levels of antifungal resistance [5]. Keratomycosis, scleritis, and endophthalmitis are the most common ocular involvements in immunocompromised patients [6]. In fact, S. apiospermum keratitis (the most common infection of S. apiospermum in immunocompetent patients) is uncommon, aggressive, and resistant to conventional antifungal therapies [5]. Here, we report a challenging case of S. apiospermum keratitis that was successfully treated with therapeutic penetrating keratoplasty. The keratitis was resistant to fluconazole and amphotericin B and susceptible to voriconazole. In addition, we discuss treatment modalities in light of previous studies.

\footnotetext{
*Correspondence: drumutkaraca@gmail.com

Present Address: Faculty of Medicine Department of Ophthalmology,

Suleyman Demirel University, Isparta, Turkey
}

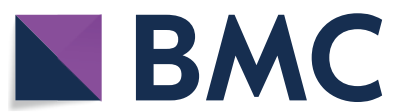

(c) The Author(s) 2022. Open Access This article is licensed under a Creative Commons Attribution 4.0 International License, which permits use, sharing, adaptation, distribution and reproduction in any medium or format, as long as you give appropriate credit to the original author(s) and the source, provide a link to the Creative Commons licence, and indicate if changes were made. The images or other third party material in this article are included in the article's Creative Commons licence, unless indicated otherwise in a credit line to the material. If material is not included in the article's Creative Commons licence and your intended use is not permitted by statutory regulation or exceeds the permitted use, you will need to obtain permission directly from the copyright holder. To view a copy of this licence, visit http://creativecommons.org/licenses/by/4.0/. The Creative Commons Public Domain Dedication waiver (http://creativeco mmons.org/publicdomain/zero/1.0/) applies to the data made available in this article, unless otherwise stated in a credit line to the data. 


\section{Case presentation}

A 30-year-old immunocompetent Turkish man presented to our clinic with a painful corneal abscess and severe vision loss in his left eye. His family and medical history showed no remarkable findings. The systemic examination results were not significant. He was a farmer and careless contact lens wearer. His eye symptoms started a month ago and had been treated with topical antibiotics and antiviral therapy for 2 weeks without microbiological examination. Due to disease progression despite treatment, he was referred to our tertiary ophthalmology clinic for further investigation and treatment. Visual acuity of the right eye was only light perception. Marked ciliary congestion and extensive corneal abscesses with corneal melting were observed. The anterior chamber structures were not visible because of excessive corneal abscesses (Fig. 1A). Corneal scrapings were taken immediately, and topical vancomycin $(50 \mathrm{mg} / \mathrm{ml})$, topical ceftazidime $(50 \mathrm{mg} / \mathrm{ml})$ hourly, and topical fluconazole (Fluzamed 0.3\%, World Medicine, London, England) eight times daily were started immediately.

The microbiological samples for diagnostic procedures taken from corneal tissue, contact lens, and contact lens solution were inoculated onto Sabouraud dextrose agar (SDA) and brain hard infusion (BHI) agar on the day of admission. The plates were incubated at $37{ }^{\circ} \mathrm{C}$. After 4 days of incubation, a phaeoid mold was observed on the plate, which was inoculated with a corneal tissue sample. No growth was observed in the other culture samples. The colony appearance of the fungus was white to grayish on the margin, with an olive green umbonate center and a woolly surface (Fig. 2A). The slide culture technique was used to examine the microscopic features of the fungal colonies. Direct microscopic preparation was performed using lactophenol cotton blue (LPCB) staining. The LPCB preparation showed septate hyphae with short or long slender conidiophores bearing single conidia. The conidia were oval and unicellular, with a larger end towards the apex (Fig. 2B). The mold was identified as Scedosporium apiospermum by matrix-assisted laser desorption ionization-time of flight mass spectrometry (MALDI TOF-MS) (Bruker Daltonics, Bremen, Germany). Antifungal susceptibility was studied using the gradient strip test and broth microdilution method at public health institutions. The isolate was resistant to fluconazole, amphotericin B, and miconazole, and sensitive to voriconazole.

Due to treatment unresponsiveness, fluconazole was switched to voriconazole on the third day of follow-up. Systemic voriconazole (Vfend $200 \mathrm{mg}$ intravenously, Pfizer, USA) was added every 12 hours after the antifungal susceptibility test, as it was still unresponsive on the seventh day of follow-up. Despite adequate treatment, no clinical improvement was observed, and corneal melting was observed during follow-up. Therefore, surgical intervention was performed to remove infected tissue. Therapeutic penetrating keratoplasty was performed. The purulent material colonizing the anterior chamber was aspirated and sent for microbiological examination together with the corneal button preoperatively.

A week after the surgery, a well-formed anterior chamber with moderate corneal graft edema was observed. The visual acuity of the eye was 20/125. Oral and topical voriconazole with moxifloxacin and dexamethasone were maintained for a month after surgery (Fig. 1B). The treatment is summarized in Fig. 3.

Keratoplasty sutures were excised in the sixth month after surgery. The final visual acuity of the affected eye was 20/100, and a clear donor cornea and silent

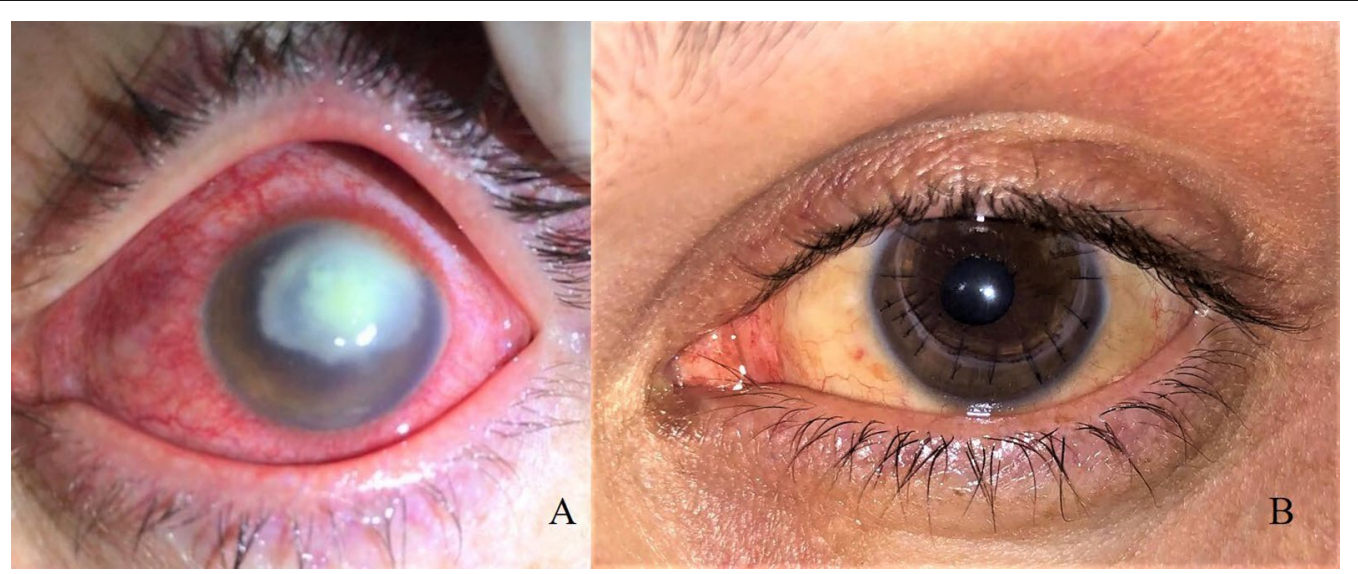

Fig. 1 A Keratitis with excessive corneal abscess. B Postoperative first month of the patient. 


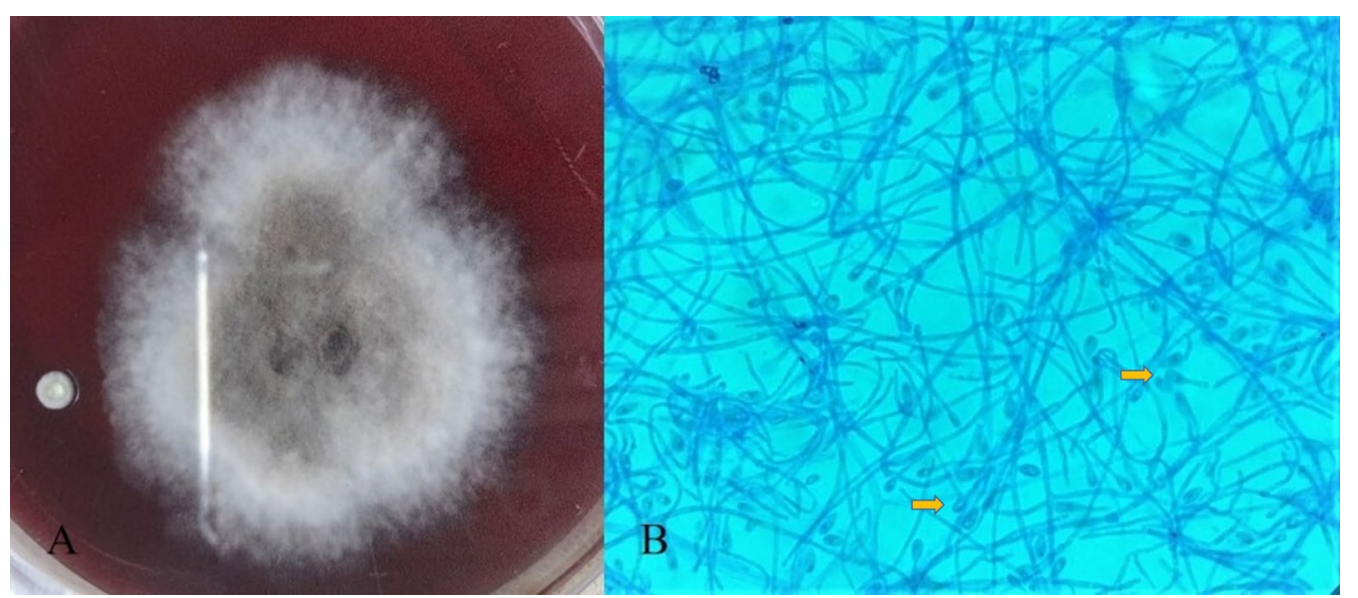

Fig. 2 A Colony morphology of Scedosporium apiospermum on brain hard infusion agar. Colony appearances of the fungus were white to grayish on the margin with an olive-green umbonate center. B Microscopic appearance of S. apiospermium with lactophenol cotton blue stain. Septate hyphae with short or long slender conidiophores, bearing single conidia. The conidia were oval and unicellular, with the larger end toward the apex (arrows)

anterior chamber were examined during the second year of follow-up.

\section{Discussion}

S. apiospermum, an opportunistic and filamentous fungus, is a rarely seen ocular entity that is difficult to identify and heal. In this case, we would like to highlight these remarkable features. First, long-term contact lens use or misuse may predispose an immunocompetent young patient to this disease. Additionally, identification is difficult because it mimics Fusarium and Aspergillus species. Finally, penetrating keratoplasty performed at the right time is important for disease healing and vision recovery.

Environmental conditions seem to have a strong influence on the occurrence of filamentous fungal keratitis (such as Fusarium, Aspergillus, and Scedosporium) [7]. Healthy young men who are usually engaged in agriculture or other outdoor work are the main risk group for filamentous keratitis. Trauma is a predisposing factor in most diseases because of the protective features of the intact epithelium. The use of contact lenses is prominent in the formation of chronic epitheliopathies, especially in Fusarium species [8]. In recent years, Scedosporium spp. have been encountered with increasing frequency. Although the risk factors and clinical manifestations are similar to filamentous keratitis, Scedosporium species can be distinguished from others by their typical microscopic appearance and resistance to topical antifungal treatment.

There are a large number of reports of serious S. apiospermum infections in immunocompromised patients worldwide. However, keratitis is the most common manifestation of $S$. apiospermum ocular infection in immunocompetent people and, in most cases, it is usually preceded by corneal injury or contact lens misuse [9, 10]. The number of contact lens wearers is estimated to be 140 million worldwide including 750,000 in our country, and is predicted to increase gradually. Therefore, Scedosporium spp. infections are thought to be encountered more frequently [11]. Lipofuscin-like microdeposits have been shown in corneal examinations of those who wear long-term contact lenses, as a result of chronic oxygen deprivation and microtrauma, which may be associated with keratitis susceptibility [12]. The long-term use of contact lenses by an agricultural laborer (proper cornea in the proper environment), as in our patient, paves the way for this type of infection.

The diagnosis of keratomycosis begins with the suspicion of a clinical appearance and is usually defined by morphological features in culture [7]. However, hyalinized hyphal septates on direct microscopic examination complicate the distinction of Scedosporium species from Fusarium, Aspergillus, and other relatively common hyaline hyphomycetes [4]. Therefore, identification tests that support traditional methods are utilized. Various molecular techniques, such as mass spectrometry, polymerase chain reaction, and DNA sequencing, are being used for exact fungal identification. In our case, MALDI-TOFMS, a fast and reliable method for species identification of filamentous fungi, was used to identify S. apiospermum [13]. 


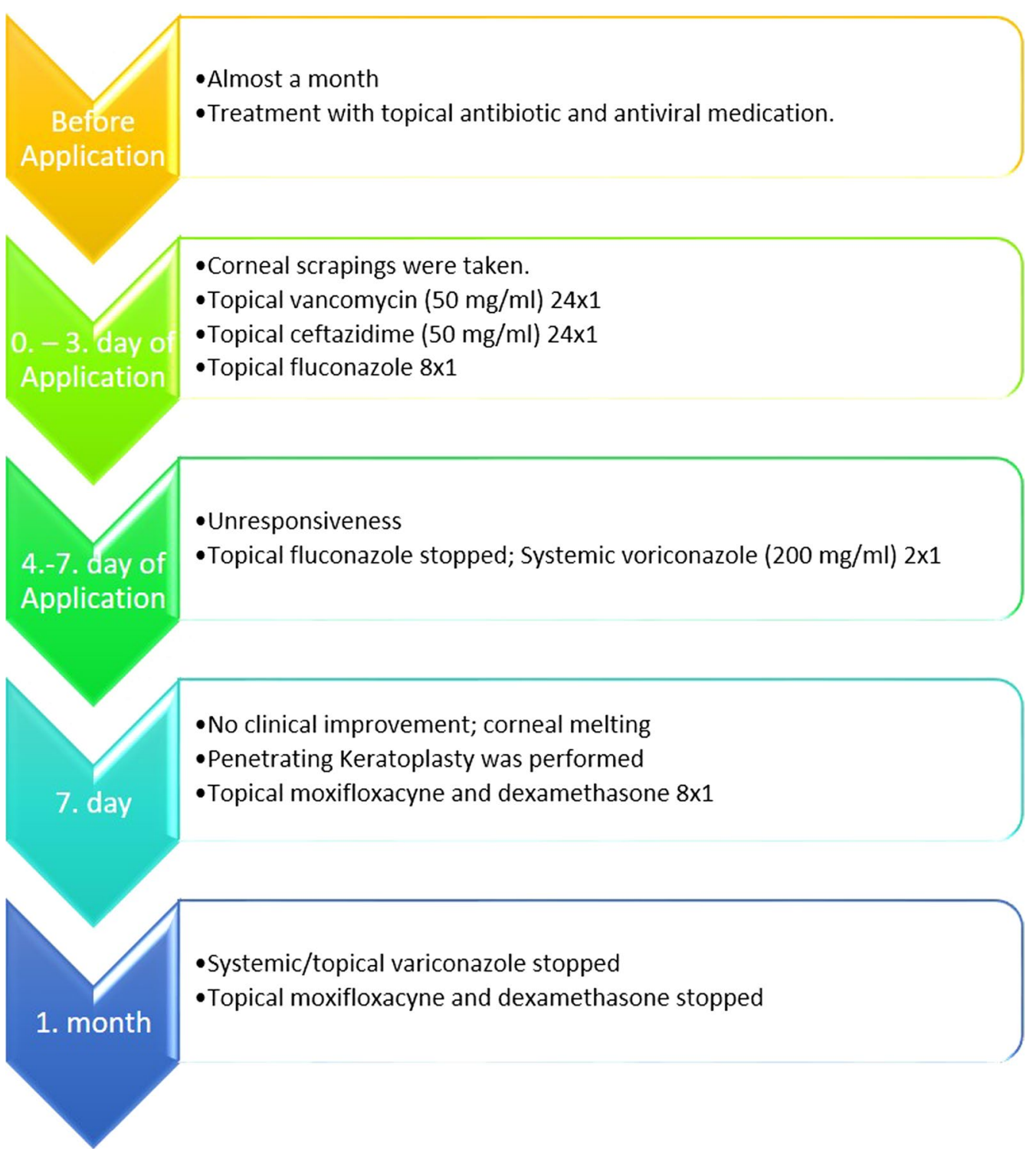

Fig. 3 Treatment SAlgorithm of the patient

Despite scientific developments, it is difficult to control keratomycosis cases with antifungal therapy because of late diagnosis and antifungal resistance. It is not yet clear which medical treatment is optimal, how long it should be used for, and when it should be stopped. Although S. apiospermum is thought to have varying susceptibilities to voriconazole, posaconazole, and miconazole, combined therapies are particularly prominent, especially for late-diagnosed invasive keratomycosis. In vitro studies have shown that a combination of azole and echinocandin is the most effective against Scedosporium isolates. However, in the treatment of keratomycosis, combined therapy is challenging because of the difficulty in finding the eye drop form of an appropriate drug and the limited effect of systemic antifungal therapy on corneal tissue. We preferred to use both systemic and topical forms of voriconazole because of its broad antifungal spectrum. However, we were unable to reach the eye drop form of natamycin, caspofungin, or amphotericin $B$ to combine.

Besides medical antifungal therapy, a literature search shows that patients undergoing penetrating keratoplasty are not rare $[10,14,15]$. The most common indications were melting and perforation. Surprisingly, in our case, voriconazole, which is a sensitive in vitro tests, could not prevent progression to necrotizing keratitis and melting, despite local and systemic administration. This can 
be explained by the spread of keratitis to all corneal layers, resulting in necrosis. Therefore, keratoplasty should be considered a treatment option in keratitis cases that have invaded all corneal layers, where it is not possible to regenerate the cornea. The timing and indications for penetrating keratoplasty should be reconsidered by ophthalmologists; otherwise, the result may be evisceration or enucleation for endophthalmitis/panophthalmitis [14].

\section{Conclusion}

S. apiospermum keratitis must be considered for both immunocompromised and immunocompetent patients, especially those with history of ocular trauma and contact lens use. Visual acuity can be increased by early diagnosis and aggressive treatment.

\section{Abbreviations}

SDA: Sabouraud dextrose agar; BHI: Brain hard infusion; LPCB: Lactophenol cotton blue; MALDI TOF-MS: Matrix-assisted laser desorption ionization timeof-flight mass spectrometry.

\section{Acknowledgements}

The author would like to thank Gokhan OZGE, MD for the contribution; and Esra Nurlu TEMEL, MD from the Clinical Microbiology and Infectious Diseases Department, for the microbiological revision of the manuscript.

\section{Authors' contributions}

The author meets the International Committee of Medical Journal Editors (ICMJE) criteria for authorship for this article, takes responsibility for the integrity of the work as a whole, and has given their approval for this version to be published. The author read and approved the final manuscript.

\section{Funding}

The authors declare that no funding or sponsorship was received for this case report or the publication of this article.

\section{Availability of data and materials}

Data sharing is not applicable to this article, as no datasets were generated or analyzed during the current study.

\section{Declarations}

\section{Ethical approval and consent to participate}

The procedures in this case report were conducted in accordance with the tenets of the Declaration of Helsinki. The subject provided consent to participate in this study. No identifiable patient information has been provided in this manuscript.

\section{Consent for publication}

Written informed consent was obtained from the patient for publication of this case report and any accompanying images. A copy of the written consent is available for review by the Editor-in-Chief of the journal.

\section{Competing interests}

The author has no conflicts of interests to disclose.

Received: 14 December 2021 Accepted: 4 February 2022

Published online: 04 March 2022

\section{References:}

1. Brown GD, Denning DW, Gow NAR, Levitz SM, Netea MG, White TC. Hidden killers: human fungal infections. Sci Transl Med. 2012. https://doi.org/ 10.1126/scitranslmed.3004404.

2. Khwakhali US, Denning DW. Burden of serious fungal infections in Nepal. Mycoses. 2015;58:45-50. https://doi.org/10.1111/myc.12393.

3. Hilmioğlu-Polat S, Seyedmousavi S, Ilkit M, Hedayati MT, Inci R, Tumbay E, Denning DW. Estimated burden of serious human fungal diseases in Turkey. Mycoses. 2019;62(1):22-31. https://doi.org/10.1111/myc.12842.

4. McCarthy MW, Katragkou A, losifidis E, Roilides E, Walsh TJ. Recent advances in the treatment of Scedosporiosis and Fusariosis. J Fungi (Basel, Switzerland). 2018. https://doi.org/10.3390/JOF4020073.

5. Guarro J, Kantarcioglu AS, Horré R, Rodriguez-Tudela JL, Cuenca Estrella M, Berenguer J, de Hoog GS. Scedosporium apiospermum: changing clinical spectrum of a therapy-refractory opportunist. Med Mycol. 2006:44(4):295-327. https://doi.org/10.1080/13693780600752507.

6. Mochizuki HKK. Fungal endophthalmitis. Japanese J Clin Ophthalmol. 2016;70(11):286-95. https://doi.org/10.1097/iae.0b013e318185e943.

7. Thomas PA, Kaliamurthy J. Mycotic keratitis: epidemiology, diagnosis and management. Clin Microbiol Infect. 2013. https://doi.org/10.1111/14690691.12126.

8. Ramakrishnan T, Constantinou M, Jhanji V, Vajpayee RB. Factors affecting treatment outcomes with voriconazole in cases with fungal keratitis. Cornea. 2013;32(4):445-9. https://doi.org/10.1097/ICO.0B013E318254A41B.

9. Arthur S, Steed LL, Apple DJ, Peng Q, Howard G, Escobar-Gomez M. Scedosporium prolificans keratouveitis in association with a contact lens retained intraocularly over a long term. J Clin Microbiol. 2001;39(12):4579-82. https://doi.org/10.1128/JCM.39.12.4579-4582.2001.

10. Lenk J, Raiskup F, Pillunat LE, Rößler S. Scedosporium apiospermum—a rare pathogen of keratomycosis. Ophthalmologe. 2020;117(12):1225-8. https://doi.org/10.1007/s00347-020-01073-x.

11. Cope JR, Collier SA, Rao MM, Chalmers R, Mitchell GL, Richdale K, Beach $\mathrm{MJ}$. Contact lens wearer demographics and risk behaviors for contact lens-related eye infections-United States, 2014. MMWR Morb Mortal Wkly Rep. 2015;64(32):865-70. https://doi.org/10.15585/MMWR.MM6432A2.

12. Trittibach $P$, Cadez R, Eschmann R, Sarra GM, Boehnke M, Frueh BE. Determination of microdot stromal degenerations within corneas of longterm contact lens wearers by confocal microscopy. Eye Contact Lens. 2004;30(3):127-31. https://doi.org/10.1097/01.ICL.0000131297.62881.AE.

13. Oviaño M, Rodríguez-Sánchez B. MALDI-TOF mass spectrometry in the 21st century clinical microbiology laboratory. Enferm Infecc Microbiol Clin (Engl Ed). 2021. https://doi.org/10.1016/j.eimc.2020.02.027.

14. Ramakrishnan S, Mandlik K, Sathe T, Gubert J, Krishnan T, Baskaran P. Ocular infections caused by Scedosporium apiospermum: a case series. Indian J Ophthalmol. 2018;66(1):137-40. https://doi.org/10.4103/ijo.IJO_524_17.

15. Nulens E, Eggink C, Rijs AJMM, Wesseling P, Verweij PE. Keratitis caused by Scedosporium apiospermum successfully treated with a cornea transplant and voriconazole. J Clin Microbiol. 2003;41(5):2261-4. https://doi.org/10. 1128/JCM.41.5.2261-2264.2003.

\section{Publisher's Note}

Springer Nature remains neutral with regard to jurisdictional claims in published maps and institutional affiliations.

Ready to submit your research? Choose BMC and benefit from

- fast, convenient online submission

- thorough peer review by experienced researchers in your field

- rapid publication on acceptance

- support for research data, including large and complex data types

- gold Open Access which fosters wider collaboration and increased citations

- maximum visibility for your research: over 100M website views per year

At $\mathrm{BMC}$, research is always in progress.

Learn more biomedcentral.com/submissions 